\title{
Prevalence and clinical spectrum of hypertensive retinopathy among hypertension clinic patients at Queen Elizabeth Central Hospital in Malawi
}

\section{Petros Cyrus Kayange, ${ }^{1,2}$, Markus Schulze Schwering ${ }^{1,3}$,Chatonda Stephen Manda $^{1,2}$, Isaac Singini ${ }^{4}$, Vincent Verson Phillip Moyo ${ }^{5}$, Johnstone Kumwenda ${ }^{6}$}

1, Ophthalmology Unit, College of Medicine, University of Malawi, Blantyre, Malawi

2. Lions Sight First Eye Unit, Queen Elizabeth Central Hospital, Blantyre, Malawi

3. Tübingen University Eye Hospital, Tübingen, Germany

4. Johns Hopkins Research Project, College of Medicine, University of Malawi, Malawi

5. Trinity Mission Hospital, Nsanje, Malawi

6. Department of Medicine, College of Medicine, University of Malawi, Blantyre, Malawi

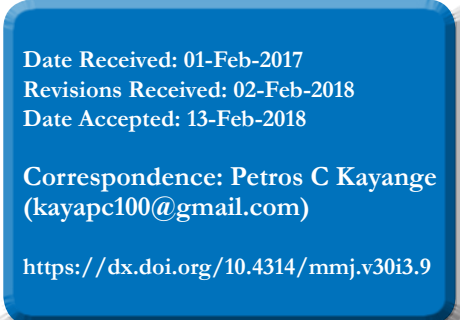

Background

\section{Abstract}

Prevalence and spectrum of hypertensive retinopathy in the population reflects the status of hypertension control and the associated risks for cardiovascular events. We investigated the prevalence and clinical spectrum of hypertensive retinopathy among patients attending hypertension clinic at a tertiary hospital in Malawi.

Methods

This was a cross-sectional study of systematically selected patients attending hypertension clinic at Queen Elizabeth Central Hospital. Patient interviews using a structured questionnaire and review of patients' medical records (health passports) were done to obtain the following information: demographics, duration since the diagnosis of hypertension, history of stroke and blood pressure measurements. The presence and severity of hypertensive retinopathy was determined by dilated fundoscopy through slit lamp biomicroscopy.

Results

We recruited 104 patients. Women outnumbered men by 3:1. Women tended to be younger compared to men (mean ages 54 and 61 years respectively). Of the surveyed patients, $80 \%$ had sub-optimal blood pressure control and $75 \%$ had evidence of hypertensive retinopathy. History of stroke was associated with hypertensive retinopathy.

Conclusions

Hypertensive retinopathy is very common in patients attending the hypertension clinic at Queen Elizabeth Central Hospital in Blantyre, Malawi. This may be a reflection of sub-optimal blood pressure control in this patient population. There is a need to identify the actual reasons, rectify them and intensify intervention in control of hypertension in this patient population.

Key words: Hypertension, Hypertensive retinopathy, Sub-Saharan Africa, Cardiovascular, Stroke

\section{Introduction}

The World Health Organization (WHO) has warned that developing countries are sitting on a time bomb of noncommunicable diseases (NCDs), and hypertension is one of them ${ }^{1}$. Data on the prevalence and control of hypertension is sparse in sub-Saharan Africa (SSA). Where data has been obtained, hypertension seems to be very common. A STEPS nationwide survey of hypertension in Malawi commissioned by the WHO found high hypertension prevalence $(33 \%)$ among adults together with a large number of risk factors for $\mathrm{NCDs}^{2}$. Data from similar surveys elsewhere shows similar high prevalence of hypertension in African communities ${ }^{3,4}$. Awareness, detection and treatment and control of hypertension in SSA are all low ${ }^{4}$. As a result, many patients present for the first time to health care providers with evidence of end organ damage. Among those that are in care, drug stock outs and other health structural barriers may make the control of hypertension difficult. Therefore, there are high rates of cardiovascular morbidity and mortality associated with hypertension in the region ${ }^{5}$.

Hypertensive retinopathy is a spectrum of retinal signs related pathologically to retinal microvascular damage from elevated blood pressure ${ }^{6}$. It is well documented that hypertensive retinopathy is associated with cardiovascular morbidity and mortality ${ }^{7-9}$.Therefore, prevalence and spectrum of hypertensive retinopathy in the population reflects the status of hypertension control and the associated risks for cardiovascular events. In clinical management of hypertensive patients, hypertensive retinopathy can be used in cardiovascular risk assessment ${ }^{9}$ and can be an indication for initiating anti-hypertensive therapy, even in persons with pre-hypertension or stage one hypertension ${ }^{10,11}$.

We conducted a hospital based cross-sectional study in Blantyre-Malawi in order to determine the prevalence and pattern of hypertensive retinopathy among patients attending a hypertension clinic at a tertiary hospital.

\section{Methodology}

\section{Setting}

This cross-sectional study was conducted at Queen Elizabeth Central Hospital (QECH) in Blantyre, Malawi, between July and August 2014. QECH is the largest tertiary and teaching hospital in Malawi for nurses, clinical officers, 
levels. It has a large secondary level but small tertiary level service and there is no dedicated government district hospital in Blantyre.

Hypertension clinics are conducted on Tuesday and Friday mornings. Approximately 80 patients attend each clinic. The drug supply is erratic at best and the commones
anti-hypertensive medications include propranolol, anti-hypertensive medications include propranolol, converting enzyme (ACE) inhibitors and calcium channel inhibitors are at times available. Patients are seen once every 3 months but drug supply is usually provided for only 1 month because of rationing

\section{Sampling}

Our minimum sample size (97) was based on the reported prevalence of $60 \%$, with a margin of $5 \%$ and this gives the study power of above $80 \%$. We used the following sample size formula:

$\mathrm{N}=\mathrm{Z}_{\alpha / 2}{ }^{2} * \mathrm{p} *(1-\mathrm{p}) / \mathrm{MOE}^{2}$, where $\mathrm{Z}_{\alpha / 2}$ is the critical value of the Normal distribution at $\alpha / 2$, MOE is the margin of error, $\mathrm{p}$ is the sample proportion, and $\mathrm{N}$ is the population size. A systematic sampling method was adopted where every fourth patient on the queue at hypertension clinics at QECH was invited to participate in the study. The following was the exclusion criteria: history of diabetes mellitus, retina condition other than hypertensive retinopathy, inaccessible fundus and participant's decline to participate in the study.

\section{Data collection}

A structured interview and review of patients' medical records was done by a research assistant (a final year medical student) by use of questionnaire in order to obtain the following information: age, sex, occupation, place of residence, duration of hypertension and blood pressure measurements as recorded in patients' health passports clinic nuscs. Blood pressure is tout hy nursing staff on

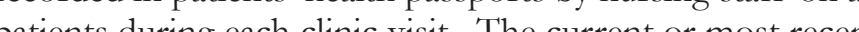
paliod pressure measurements were recorded.

Fundoscopy was done in both eyes by an ophthalmologist through slit lamp biomicroscopy with hand held Volk 90 Diopter lens in order to determine the presence and severity of hypertensive retinopathy. Pupillary dilatation with Tropicamide eye drops was done before slit lamp examination. Grading of any retinopathy was done according to Mitchell-Wong simplified classification of hypertensive retinopathy

\section{Data analysis}

The data was entered and cleaned using Epidata version 3.1 and exported to the Statistical Package for Social Sciences (SPSS, version 16.0). Exploratory analysis was based on findings from the eye with more severe retinopathy using graphical techniques and frequency distributions. Categorical variables are reported as proportions while continuous variables are reported as means and standard deviation for normally distributed variables and, where appropriate, as median (IQR) for variables with a skewed distribution. Descriptive statistics were run on all baseline covariates and inferential statistics are based on the 5\% significance leve and $95 \%$ confidence interval.
Ethical clearance

The study protocol was approved by the College of Medicine conduct the study was sought from Quen Elizermission to

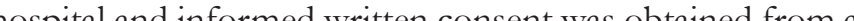
participating patients.

\section{Results}

We invited 108participants to participate in the study out of whom 104 were enrolled.. One person declined and three persons were excluded (two patients had inaccessible fundus due to dense cataracts and one patient had Uveitis)

There were 28 men $(26.9 \%)$ and 76 women $(93.1 \%)$. The demographic and clinical characteristics of the study participants are shown in Table 1.

Table 1: Demographic and clinical characteristics of the study participants

\begin{tabular}{|l|l|l|l|l|} 
& Males & Female & All & $p$ value
\end{tabular}$\quad$\begin{tabular}{l}
$\begin{array}{l}\text { with the prevalence of hypertensive retinopathy on univariate } \\
\text { analysis (Table 3). }\end{array}$ \\
\hline
\end{tabular}

\begin{tabular}{|c|c|c|c|}
\hline $\begin{array}{l}\text { age in } \\
\text { vears }\end{array}$ & $01.3(12.2)$ & $53.9(12.5)$ & $\begin{array}{l}55.9 \\
(12.8\end{array}$ \\
\hline
\end{tabular}

(SD)

Median
(IQR)

(IQR)
time
since

diagnosi

in years

Time from
diagnosis

of

$<3$ years

$3(2-9)$

3
$(2-9)$

$3-4$ years

$\geq 5$ years

BP
classification

Controlled

(<140/90 mm Hg)

Grade 1 (mild)

\begin{tabular}{|l|l|l|l|l|}
\hline $\begin{array}{l}\text { Grade 2 } \\
\text { (moderate) }\end{array}$ & $5(17.9 \%)$ & $20(27.0 \%)$ & $\begin{array}{l}25 \\
(24.5 \%)\end{array}$ & \\
\hline Grade 3 (severe) & $9(32.1)$ & $23(31.1 \%)$ & 32 & 0.782 \\
\hline
\end{tabular}

\begin{tabular}{|l|l|l|l|l|l|}
\hline $\begin{array}{l}\text { On treatment } \\
\text { of }\end{array}$ & $28(100.0 \%)$ & $12(96.0 \%)$ & $\begin{array}{l}100 \\
(97.1 \%)\end{array}$ & 0.283 \\
\hline
\end{tabular}

hypertension

\begin{tabular}{|l|l|l|l|l|}
\hline $\begin{array}{l}\text { History } \\
\text { of stroke }\end{array}$ & $8(28.6 \%)$ & $7(9.3 \%)$ & $\begin{array}{l}15 \\
(14.6 \%)\end{array}$ & 0.014 \\
\hline
\end{tabular}

Women were significantly younger $(\mathrm{p}=0.008)$ and were less likely to have had history of stroke than men $(\mathrm{p}=0.014)$. hypertensive medications at the time of the study. The prevalence of hypertensive retinopathy is shown in Table 2.

https://dx.doi.org/10.4314/mmj.v30i3.9 (a) 3).

Table 3: Factors associated with prevalence of hypertensive retinopathy

\begin{tabular}{|c|c|c|c|}
\hline Grade $^{*}$ & Number & Percentage & $95 \% \mathrm{Cl}$ \\
\hline Any retinopathy & 78 & $75.0 \%$ & $66.7-83.3 \%$ \\
\hline Mild retinopathy & 73 & $70.2 \%$ & $61.4-79.0 \%$ \\
\hline Moderate retinopathy & 5 & $4.8 \%$ & $0.7-8.9 \%$ \\
\hline
\end{tabular}
66.7-83.3\%) in our setting. Mild hypertensive retinopathy malignant hypertensive grade. There

We a so stulied he association beween the pevalence Wrevalence of retinopathy and factors such as sex, old age, history of

\begin{tabular}{|c|c|c|c|c|c|}
\hline \multirow{2}{*}{\multicolumn{2}{|c|}{\begin{tabular}{l|l} 
& \\
$\begin{array}{l}\text { Risk factor } \\
\text { (unit of measurement) }\end{array}$
\end{tabular}}} & \multicolumn{2}{|c|}{ Retinopathy } & \multirow[b]{2}{*}{$\mathrm{N}$} & \multirow[b]{2}{*}{ P-Value } \\
\hline & & Present & Absent & & \\
\hline \multirow[t]{2}{*}{ Sex: n (\%) } & Male & $\begin{array}{l}19 \\
(73.08)\end{array}$ & \begin{tabular}{|l}
7 \\
$(26.92)$ \\
\end{tabular} & 26 & \multirow[t]{2}{*}{1.00} \\
\hline & Female & $\begin{array}{l}57 \\
(73.08)\end{array}$ & \begin{tabular}{|l|}
21 \\
$(26.92)$ \\
\end{tabular} & 78 & \\
\hline Age years & $\begin{array}{l}\text { Mean } \\
\text { (SD) }\end{array}$ & $\begin{array}{l}56.0 \\
(10.7)\end{array}$ & \begin{tabular}{|l|}
57.8 \\
$(14.2)$ \\
\end{tabular} & 103 & 0.48 \\
\hline $\begin{array}{l}\text { Time since } \\
\text { diagnosis } \\
\text { in years }\end{array}$ & $\begin{array}{l}\text { Median } \\
\text { (IQR) }\end{array}$ & $\begin{array}{l}4 \\
(2,8.5)\end{array}$ & $\begin{array}{l}3 \\
(2,10)\end{array}$ & 102 & 0.94 \\
\hline \multirow[t]{4}{*}{$\begin{array}{l}\text { BP } \\
\text { classification: } \\
\text { n (\%) }\end{array}$} & \begin{tabular}{|l|} 
Controlled \\
$(<140 / 90$ \\
$\mathrm{mm} \mathrm{Hg})$ \\
\end{tabular} & \begin{tabular}{|l|}
13 \\
$(72.2)$
\end{tabular} & \begin{tabular}{|l|}
5 \\
$(27.8)$
\end{tabular} & 18 & \multirow[t]{4}{*}{0.68} \\
\hline & $\begin{array}{l}\text { Grade } 1 \\
\text { (mild) }\end{array}$ & $\begin{array}{l}21 \\
(77.8)\end{array}$ & \begin{tabular}{|l}
6 \\
$(22.2)$
\end{tabular} & 21 & \\
\hline & $\begin{array}{l}\text { Grade } 2 \\
\text { (moderate) }\end{array}$ & \begin{tabular}{|l|}
17 \\
$(68.0)$
\end{tabular} & \begin{tabular}{|l|}
8 \\
$(32.0)$ \\
\end{tabular} & 25 & \\
\hline & $\begin{array}{l}\text { Grade } 3 \\
\text { (severe) }\end{array}$ & \begin{tabular}{|l}
26 \\
$(81.4)$ \\
\end{tabular} & \begin{tabular}{|l}
6 \\
$(16.6)$ \\
\end{tabular} & 32 & \\
\hline \multirow{2}{*}{$\begin{array}{l}\text { Treatment of } \\
\text { hypertension: } \\
\text { n(\%) }\end{array}$} & Yes & $\begin{array}{l}76 \\
(76.0)\end{array}$ & \begin{tabular}{|l|}
24 \\
$(24.0)$ \\
\end{tabular} & 100 & \multirow[t]{2}{*}{0.16} \\
\hline & No & $\begin{array}{l}1 \\
\text { (33.3) } \\
\end{array}$ & \begin{tabular}{|l}
2 \\
$(67.7)$ \\
\end{tabular} & 3 & \\
\hline \multirow{2}{*}{$\begin{array}{l}\text { History } \\
\text { of stroke: } \\
\text { (1) } \%)\end{array}$} & Yes & $\begin{array}{l}15 \\
(100)\end{array}$ & 0 & 15 & \multirow[t]{2}{*}{0.019} \\
\hline & No & $\begin{array}{l}63 \\
(71.6)\end{array}$ & \begin{tabular}{|l}
25 \\
(26.4)
\end{tabular} & 88 & \\
\hline
\end{tabular}

\section{Discussion}

In this study, we found a high prevalence of uncontrolled systemic hypertension and a high prevalence of both hyperalence of stroke was higher in men than women and this difference was statistically significant. We also found that prevalent stroke was associated with hypertensive retinopaprevalen
thy. prising as previous stodies in Mrani have described sinith
The prevalence of retinopathy was high $(75.0 \%, 95 \%$ CI

Only a few of our study participants had controlled hyper- findings $\mathrm{s}^{13,14}$. The previous studies in Malawi also found that hypertension control is a result of many factors including lack of medication and essential equipment, inadequate knowledge and skills of health workers and low clinic patient attendance rates ${ }^{13,14}$. We found a very high prevalence of mild hypertensive retinopathy $(70.2 \%)$ among our study participants. This is similar to a study done in Ghana among civil servants where the prevalence of mild grades of retinopathy among hypertensive persons was as high as $69.4 \%$ The high prevalence of mild hypertensive retinopathy mong our study participants is not surprising because there was high prevalence of uncontrolled hypertension. We did not find severe hypertensive retinopathy. We think this was mainly because hypertensive patients with end organ damage such as renal failure and hypertensive heart diseases are seen in renal and chest clinics respectively.

Large population based studies done outside Africa have demonstrated that hypertensive retinopathy is associated with cardiovascular morbidities such as coronary cardiac disease and left ventricular hypertrophy and stroke $e^{10,16}$. We found in our study participants that hypertensive retinopathy was associated with history of stroke. Previous studies have demonstrated hypertensive retinopathy as an independent risk factor for incident or subclinical stroke even in patients with controlled hypertension ${ }^{10,16}$. Future studies are needed to identify the relationship between prevalent stroke and hypertensive retinopathy in Africa in persons with controlled hypertension. It would have been interesting to study the association between hypertensive retinopathy and other cardiovascular morbidities such as coronary cardiac disease, left ventricular hypertrophy and renal dysfunction. However, this was not possible within the confines of our current study. Our study had some limitations. Some diseases such as diabetic retinopathy can present with similar features as in hypertensive retinopathy. We excluded patients with history of diabetes mellitus. However, we did not carry out laboratory tests such as fasting blood glucose to rule out the possibility of diabetic retinopathy especially in patients with moderate hypertensive retinopathy, and this may potentially have led to overestimation of prevalence of moderate hypertensive retnopathy. Secondly, we did not measure blood pressure during the study. We recorded blood pressure that we clinic visit. This could the potentially led to misclarsifcation of the sevity of hypertension as the to misclassification of the severity of hypertension as the blood pressure due to busy nature of the clinic Nevertheless, our study had due to busy he of the previous studies on study had sive reting tion or its modification in grading of hypertensive retincathy. This classification system is associated with difficulty in distinguishing the lower grades of retinopathy ${ }^{1}$ in clinial practice. We used a new grading system called MitchellWong Simplified classification which is reliable in classifying examined both eyes of the study participants and analyzed he eye with worse hypertensive retinopathy, therby minimizing chances of missing any retinopathy.

\section{Conclusion}

Our study has shown high prevalence of uncontrolled hypertension, high prevalence of hypertensive retinopathy, and that hypertensive retinopathy is associated with history among clinic patient population must be intensified. Further 
studies are needed to identify the association of hypertensive retinopathy with other cardiovascular morbidities and also to identify the association of hypertensive retinopathy with stroke in patients with controlled hypertension.

\section{Acknowledgement}

We are very grateful to Dr. Boston Zimba and Ms. Catheline Lunduka for taking part in the participants' recruitment process and data entry respectively.

\section{References}

1. World Health Organization. Global health risks: mortality and burden of disease attributable to selected major risks. World Health Organization; 2009. http://www.who.int/healthinfo/global_burden_ disease/GlobalHealthRisks_report_full.pdf

2. Msyamboza KP, Ngwira B, Dzowela T, Mvula C, Kathyola D, Harries AD, et al. The Burden of Selected Chronic Non-Communicable Diseases and Their Risk Factors in Malawi: Nationwide STEPS Survey. PLoS One. 2011 May 23;6(5):e20316. doi: 10.1371/journal. pone. 0020316

3. Goma FM, Nzala SH, Babaniyi O, Songolo P, Zyaambo C, Rudatsikira E, et al. Prevalence of hypertension and its correlates in Lusaka urban district of Zambia: a population based survey. Int Arch Med. 2011;4(1):34. doi: 10.1186/1755-7682-4-34

4. Hendriks ME, Wit FW, Roos MT, Brewster LM, Akande TM, de Beer $\mathrm{IH}$, et al. Hypertension in sub-Saharan Africa: cross-sectional surveys in four rural and urban communities. PloS One. 2012;7(3):e32638. doi: 10.1371/journal.pone.0032638

5. Cappuccio FP, Miller MA. Cardiovascular disease and hypertension in sub-Saharan Africa: burden, risk and interventions. Intern Emerg Med. 2016;11(3):299-305. doi: 10.1007/s11739-016-1423-9

6. Kanski JJ, Bowling B. Clinical ophthalmology: a systematic approach. Elsevier Health Sciences; 2011.

7. Wong TY, Klein R, Couper DJ, Cooper LS, Shahar E, Hubbard LD, et al. Retinal microvascular abnormalities and incident stroke: the Atherosclerosis Risk in Communities Study. Lancet.
2001;358(9288):1134-40. doi: 10.1161/01.STR.0000195134.04355.e5

8. Wong TY, Klein R, Sharrett AR, Duncan BB, Couper DJ, Tielsch JM, et al. Retinal arteriolar narrowing and risk of coronary heart disease in men and women: the Atherosclerosis Risk in Communities Study. JAMA. 2002;287(9):1153-9.

9. Grosso A, Veglio F, Porta M, Grignolo FM, Wong TY. Hypertensive retinopathy revisited: some answers, more questions. Br J Ophthalmol. 2005;89(12):1646-54. doi: 10.1136/bjo.2005.072546

10. Baker ML, Hand PJ, Wang JJ, Wong TY. Retinal signs and stroke: revisiting the link between the eye and brain. Stroke. 2008;39(4):13719. doi: 10.1161/STROKEAHA.107.496091

11. Ramsay LE, Williams B, Johnston GD, MacGregor GA, Poston L, Potter JF, et al. British Hypertension Society guidelines for hypertension management 1999: summary. BMJ. 1999;319(7210):630-5. doi: https:// doi.org/10.1136/bmj.319.7210.630

12. Wong TY, Mitchell P. Hypertensive retinopathy. N Engl J Med. 2004;351(22):2310-7. doi: 10.1056/NEJMra032865

13. Manjomo RC, Mwagomba B, Ade S, Ali E, Ben-Smith A, Khomani $\mathrm{P}$, et al. Managing and monitoring chronic non-communicable diseases in a primary health care clinic, Lilongwe, Malawi. Public Health Action. 2016;6(2):60-5. doi: 10.5588/pha.16.0003

14. Wood R, Viljoen V, Van Der Merwe L, Mash R. Quality of care for patients with non-communicable diseases in the Dedza District, Malawi. Afr J Prim Health Care Fam Med. 2015;7(1):1-8. http://dx.doi. org/10.4102/phcfm.v7i1.838

15. Addo J, Smeeth L, Leon DA. Hypertensive target organ damage in Ghanaian civil servants with hypertension. PLoS One. 2009;4(8):e6672. https://doi.org/10.1371/journal.pone.0006672

16. Ong Y-T, Wong TY, Klein R, Klein BE, Mitchell P, Sharrett AR, et al. Hypertensive Retinopathy and Risk of Stroke. Hypertension. 2013; 62(4):706-11. doi: 10.1161/HYPERTENSIONAHA.113.01414 